\title{
Agroecology, Sovereignty and the Endogenous Development Perspective in Seed Governance and Management
}

\section{Yoshiaki Nishikawa}

\begin{abstract}
Food sovereignty is a useful concept for researchers, officials and activists eager to understand on-the-ground realities in the context of seed governance. For the Indigenous, peasant and small farmers immersed in those realities, however, it can seem abstract, prescriptive and politicised. In this analysis of the broader debate, Yoshiaki Nishikawa suggests that the Japanese sociologist Kazuko Tsurumi's endogenous development theory offers a perspective applicable to myriad seed-sovereignty approaches. That perspective puts farmers' work experience and cultural values first, recognises and supports a genuinely inclusive seed commons and infuses an understanding of rural realities and spontaneous practices into the study and practice of agroecology. Tsurumi emphasised that transformation is never complete: traditional customs and approaches
\end{abstract}

Y. Nishikawa $(\bowtie)$

Ryukoku University, Kyoto, Japan

e-mail: nishikawa@econ.ryukoku.ac.jp

Y. Nishikawa and M. Pimbert (eds.), Seeds for Diversity and Inclusion, https://doi.org/10.1007/978-3-030-89405-4_13 
coexist with modern introductions. Thus, the heterogeneous nature of those who manage seeds, and of the resources themselves, needs to be grasped by scientists and policymakers in this arena. As Nishikawa concludes, it is local decisions, not external ideologies, that must come first in guiding analyses on building better seed management systems.

Keywords Colonization · Endogenous development · Kazuko Tsurumi $\cdot$ Self determination $\cdot$ Spontaneous practice

\subsection{INTRODUCTION}

In many studies on seed governance, debates hinge on a certain set of polarities: traditional vs. modern, subsistence vs. commercial or local vs. global, for instance. Recently, rights-based approaches to seed governance have emerged as a key area of discussion.

A rights-based approach views human rights and democracy as universal values. It is a powerful way of advocating the value of seed sovereignty for a more sustainable society. Yet it can be a doubleedged sword. From the perspective of governance and management, such labelling may override the important values seeds carry for Indigenous and lay people, arising from their commitment to and care of this vital resource based on their own systems and practices. There is plenty of active research on sustainable methods of procuring seeds, especially within political economy and political ecology, with the aim of highlighting the pivotal role of seeds in agroecology (Levidow et al., 2014; Pimbert, 2018a, 2018b; Rosset \& Altieri, 2017, also see Chapter 1).

Concepts of food sovereignty and agroecology can be a powerful lens on how interested parties in local contexts can-through commitment, care and adaptive behaviour-foster resilience in seed governance (see also Chapter 3). Food sovereignty can also be a useful tool for third parties (such as researchers, government officials and civil society activists) who need to understand and discuss the activities of those directly involved in seed governance. However, globally, there are many communities where people cherish their own ways of maintaining seed systems that are quite 
outside Western notions of sovereignty, as described in Chapters 4, 5, and 6. As many Indigenous and peasant movements seeking autonomy advocate, sovereignty needs to be seen from the perspectives of those involved, not those of outsiders (Chambers, 2005; Nishikawa \& Hamaguchi, 2018; Scoones, 2015).

\subsection{Agroecological Framing of Seed Governance Debates}

As agricultural modernisation has advanced, seeds have become objects with economic value, serving as counters in market transactions. Yet at the same time, there has been a gradual rise in global awareness of how farmers contribute to crop diversity.

The unsustainable nature of today's resource-consuming and environmentally destructive food and agriculture systems has been widely recognised. Amid growing interest in establishing sustainable alternatives, agroecology as a concept and field has drawn much attention. The Food and Agriculture Organization of the United Nations (FAO) described ten components as conditions of agroecology: diversity, cocreation and sharing of knowledge, synergies, efficiency to reduce external input, recycling, resilience, human and social values, cultural and food traditions, responsible governance, and a circular and solidarity economy. The organisation notes that the introduction of agroecology is transforming the current system, and also has an affinity with farmer-centred approaches (FAO, 2018). Meanwhile, Peter Rosset and Miguel Altieri (2017), leading advocates of agroecology, view the practice and field as integrating science, agricultural practice and social movements (also see Fig. 13.1).

Colin Anderson and colleagues (2020) identified six 'domains of transformation', or interfaces between the existing food system and agroecological potential: access to natural ecosystems, knowledge and culture, systems of exchange, networks, equity and discourse. They go on to describe conditions in each domain that enable or disable the transition to agroecology as a way of evaluating existing policies, institutions and practices. Cross-sections of these domains and different spatial scalesfrom household to community, territory, national and international-are proposed as important places for this transformation and the uptake of agroecology as a science, practice and social movement. Anderson and his coauthors conclude that the more different domains overlap, 


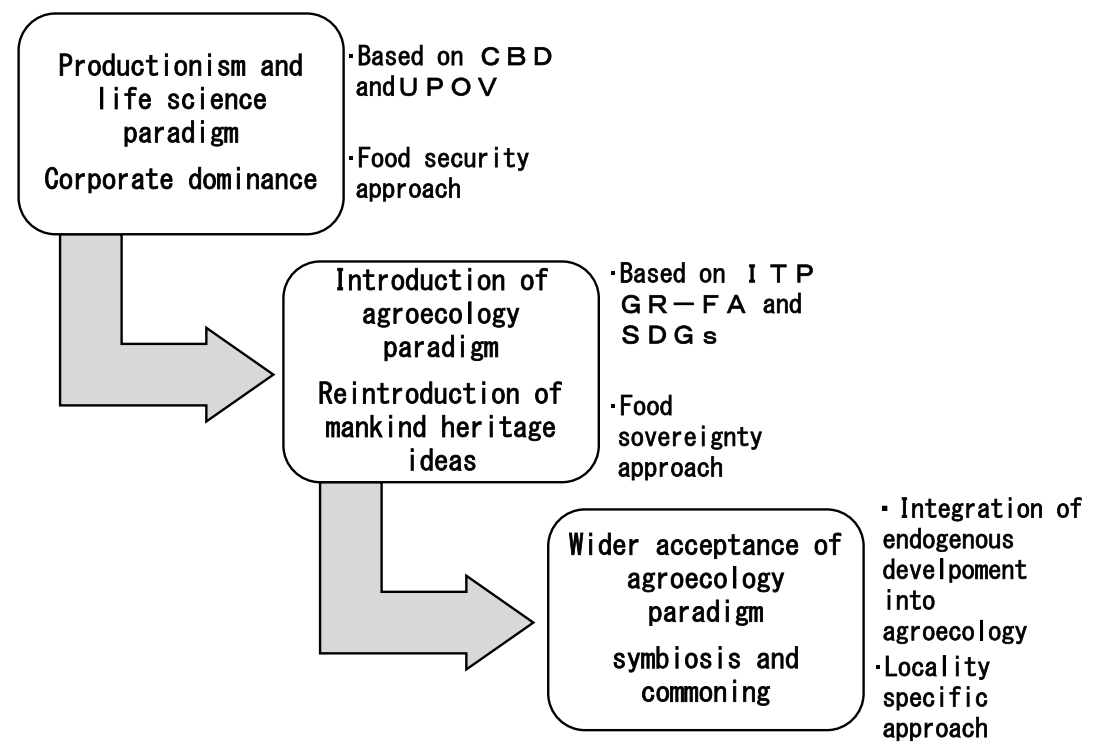

Fig. 13.1 Transformation of seed governance and management; a concept flow (by Author based on Ikegami (2019), Nishikawa (2019))

the greater the potential for durable, pervasive and deep agroecological transformation.

\subsection{Putting Farmers First in Seed Governance ANd Management}

To enrich debates on agroecologically based seed systems, I propose endogenous development theory as a way of describing practices aimed at resilience in Asia and elsewhere (see Chapter 3). The Japanese sociologist Kazuko Tsurumi advocated the endogenous development perspective as key to finding self-determined ways of resource management and development in specific localities, particularly in places touched by environmental disasters such as Minamata, where mercury poisoning from industrial sources led to widespread disease (Tsurumi, 1996; Box 3.1). This perspective, derived from biological concepts of symbiosis, is applicable to a 
spectrum of approaches to seed sovereignty, such as those seen in this book.

To understand the realities of local people and the rationales behind their processes of knowing and decision making, outsiders need to cultivate a particular outlook: to see not only explicitly observable actions and institutions, but also the process and context behind them (Pimbert 2018b). For instance, Masayoshi Shigeta (1994), over years of research in Ethiopia on the concerns and independence of local farmers, offers perspectives for understanding African agriculture. Before the 1970s, socalled traditional agriculture in Africa, especially mixed cropping, was perceived by Western scholars and development workers as unproductive and inefficient in terms of resource management. Over time, Western observers and theorists gradually realised that such traditional cultivation methods are scientifically sound, as they make effective use of soils and water, help in pest control and contribute to a fair distribution of labour.

Such a shift in perception may be seen as progress, at least in its reevaluation of farmers in Africa. But it is really a cautionary tale in how basing judgement on Western ideas of efficient use of resources (for example) can override the unique experiential wisdom of small farmers. It is necessary to understand the knowledge and ways of knowing that people living in a specific locality have evolved (Sota, 2000; and see Box 13.1).

\section{Box 13.1: Garden Fruit Trees in Japan: Unpaid Labour, Local Values and Maintenance of Diversity}

A number of farmers in rural areas of Nagano and Yamagata Prefectures have kept fruit trees in their gardens for many years. The particular municipalities the author visited are famous for their innovative agriculture for small-scale commercial production. Although little economic benefits accrue from these garden orchards, they continue to cultivate them, primarily to provide fruit for family consumption. Typically, they grow persimmon, chestnuts, akebi (chocolate vine), silverberry, plums and pears. Surplus crops are used as gifts exchanged among community residents, especially women.

The cultivation tends to be 'relaxed' and low maintenance, with the work limited to pruning and disinfecting. Despite this, the household heads involved in the practice explicitly recognise the value of their trees as an important ancestral legacy. 
Although all five family heads the author visited appeared not to have strong feelings about uses for the fruits, their wives have continued processing them and preserving the 'taste of family'. While buying agricultural products has become a norm even for farmers, home-processed foods are felt to have a desirable, non-standardised taste.

By maintaining garden orchards, farmers, both household heads and their wives, enjoy non-paid work for 'relaxed care' and 'home processing'. These local spontaneous behaviours, based on their own values and persisting free of external oversight, are prime examples of endogenous development to maintain crop diversity in local areas.

Source: Owada, H. (2019). Nouka no niwaki kaju no riyou ni miru seizon seikatsuteki na kachi ni kansuru ichi kousatsu [A study on the survival and lifestyle values of farmers' use of fruit trees: From the viewpoint of vernacular and conviviality] Kyosei Studies, 13(1), 98-118.

Agriculture and rural development are applied knowledge, and scientific universalism alone cannot solve or describe their complexities. Farmers' behaviours and decisions depend on local and cultural identities established over time, and based on socioeconomic and political conditions as well as national development policies (Chambers, 2005). Bhutan is a case in point (see Chapter 11). The experience of that nation shows the necessity of a triple approach mingling knowledge of natural science, specific cultural values, and inclusive collaboration in deciding the development strategy of the country.

It is thus key for researchers to understand the seed system from a comprehensive range of viewpoints. If such a deductive flow exists, from the field to the realms of research and policy, agroecology can gain ground in many different societies (Yamane \& Ito, 2019).

\subsection{The Seed Commons AND ENDOGENOUS DEVELOPMENT}

Tsurumi clearly distinguished between 'bottom-up' and 'top-down' endogenous development (Tsurumi, 1996). In her view, endogenous development should be a social movement in which local residents act or even protest against the central or local governments that promote modernisation policies. However, in many cases, endogenous development can be part of policy, in that central or local governments intend 
to incorporate into their policies the regional development promoted by local residents who utilise the ecosystem and traditional culture of their community. When concepts to do with agroecology and food sovereignty are imposed on local communities without their consent, the identity and dignity of local stakeholders are eroded.

To avoid this new form of colonisation masquerading as agroecology, many examples gathered in this book offer insights into how to foster diversity and inclusion. They show that diversity can be encouraged in technologies (the integration of hybrid varieties in Bhutan, Chapter 11); networking (cases from Myanmar, Chapter 6; and East Asia, Chapter 7); organisations (small-scale seed companies with family-oriented aspects in Japan, Chapter 10); and strategies (evolutionary breeding, Chapter 8; and seed savers in Japan, Chapter 5).

Individual cases and contexts reveal the overlap between agroecology and endogenous development. Both of these practices also stress the relationship between the environment and the human, and among the environment, science and technology. But there are differences between the two. Endogenous development does not aim to transform the system and the balance of power, which Tsurumi describes as a nonconfrontational integrative approach (see Box 3.1). The agroecological aim, meanwhile, is to transform the system through politics as a universally applicable approach, while upholding the imperative to keep within planetary limits.

Shuji Hisano (2017), a researcher and advocate of rights to food, analyses international research trends in the concept of food sovereignty. His work indicates that while food security as a concept is related to normative purpose (a result to be achieved), food sovereignty is related to normative process (paths to be taken or methods to be adopted). An international framework based on rights brings the concept of process into the interpretation of food sovereignty, along with the understanding that agricultural activities are an ongoing reality separate from political economy. Such a framework has the potential to connect agricultural realities with international debates.

Seeds, as biological resources and crop genetic resources, were originally regarded as the common heritage of humankind, well maintained under a diversity of management systems and practices for the commons in specific places. As globalisation and industrialisation have taken hold, commercial control over these resources has grown, to the point where 
many who are reliant on seeds for livelihoods, identity and tradition have lost the capacity to maintain them sustainably.

As argued in Chapter 12, this situation calls for a re-commoning of seeds. The multifaceted nature of seeds needs to be recognised as a global and local commons, in which the concepts and practices discussed in this section have key roles. The endogenous development perspective can foster the independent, spontaneous development of different management institutions managing local commons, such as the agricultural brokerage guild Poe Yon in Myanmar (Chapter 6), artisanal bakeries in Scotland (Chapter 9) and local seed companies in Japan (Chapter 10). And the concepts and practices of agroecology and food sovereignty can connect these institutions to form global commons, thus transforming an unsustainable seed system to a sustainable one.

\subsection{Integrating Agroecology and Food Sovereignty into SeEd Governance and Rural Development Realities}

Some researchers have established a distinction between agroecology as farming, and as a conceptual framework (Martínez-Torres \& Rosset, 2014; Rosset \& Martínez-Torres, 2012). They see agroecology as stimulating discourse that in turn inspires people to transform their farming and food systems into sustainable models. By contrast, endogenous development theory asserts that transformative shifts are never complete: customs, languages, and consciousness persist from era to era, and traditional systems and modern systems co-exist like 'uneven rows of icicles hanging down from the remote past to the present' (Tsurumi, 1975).

The idea that agriculture is life-nurturing, and that crops and seeds are entities interdependent with humans, prevails in many cultures and regions. Humans care for and nourish crops and are in turn nourished by them. In some sense, crops and humans become mutually caring partners, as described by the agronomist and smallholder farmer Yutaka Une (2018). If we adhere solely to a political, rights-based approach, where seeds are seen as controllable resources, there is a danger of yielding to neoliberal concepts of seeds' value and relying primarily on modern agrobiology rather than Indigenous knowledge and ways of knowing. We need to look beyond rights as prescriptive and see the practical management of 
seeds as a process with diverse actors involved, to realise a sustainable society and spark constructive debate.

People whose livelihoods centre on crop diversity procure seeds in truly diverse ways. They do not depend on notions of agroecology and food sovereignty - ready-made ideas brought in from outside. They only want to seek the freedom of self-determination in choosing what to grow and what to eat under the given natural, social, economic and political conditions of their locales. We, as researchers promoting agroecology and food sovereignty, should cherish these spontaneous practices as people's own endogenous ways of exercising normative process-pathways for achieving food sovereignty (see Fig. 13.1).

This book describes the efforts of various actors who manage seeds in diverse natural, social, economic and political contexts, many beset by constraints beyond their control. The heterogeneity of both actors and resources, which are key to the contexts of resource management, need to be recognised by researchers and policymakers (Louafi \& Manzella, 2018). From the endogenous development perspective, we need to be careful not to simply apply evaluation criteria set by outsiders in defining what is or is not agroecological and/or endogenous, as discussed in Chapter 3. It is clear that decisions made by locals and communities, not ideologies developed by external interests and actors, are the starting points for analyses of how to build better seed governance and management systems.

\section{REFERENCES}

Anderson, C. R., Bruil, J., Chappell, M. J., Kiss, C., \& Pimbert, M. P. (2019). From transition to domains of transformation: Getting to sustainable and just food systems through agroecology. Sustainability, 11(19), 5272. https://doi. org/10.3390/sul1195272

Chambers, R. (2005). Ideas for development. Routledge.

FAO. (2018). Agroecology knowledge hub. Retrieved August 6, 2021, from http://www.fao.org/agroecology/overview/overviewl0elements/en/

Hisano, S. (2017, February 28). Nihon kara miru food sovereignty, food sovereignty kara miru Nihon [Japan from the perspective of food sovereignty, food sovereignty from the perspective of Japan]. Material distributed at the FEAST Food Sovereignty Seminar. Retrieved July 26, 2021, from https:// www.researchgate.net/publication/325381570_Japan_from_the_Perspective_ of_Food_Sovereignty_Food_Sovereignty_from_the_Perspective_of_Japan_shi liaozhuquankarajianruriben_ribenkarajianrushiliaozhuquan 
Ikegami, K. (2019). SDGs jidaino nougyo nouson kenkyu, kaihatsu kyakutaikara hattenn shutai to shiteno nouminzo [A perspective of agricultural and rural studies under the era of SDGs: The necessity of shifting the notion of peasants as project targets to actors in their own development]. Journal of International Development Studies, 28(1), 1-18. https://doi.org/10.32204/jids. 28.1_1

Levidow, L., Pimbert, M. P., \& Vanloqueren, G. (2014). Agroecological research: Conforming-Or transforming the dominant agro-food regime? Agroecology and Sustainable Food Systems, 38(10), 1127-1155. https://doi. org/10.1080/21683565.2014.951459

Louafi, S., \& Manzella, D. (2018). The benefit sharing mechanisms under the international treaty; heterogeneity and equity in global resources management. In F. Girard \& C. Frison (Eds.), The commons, plant breeding and agricultural research: Challenges for food security and agrobiodiversity (pp. 257-271). Earthscan.

Martínez-Torres, M. E., \& Rosset, P. (2014). Diálogo de saberes in La Vía Campesina: Food sovereignty and agroecology. Journal of Peasant Studies, 41(6), 979-997. https://doi.org/10.1080/03066150.2013.872632

Nishikawa, Y. (2019). Jizoku kanouna shushino kanriwo kangaeru [Sustainable management of seeds: Bridging international right based framework and agro-ecology based practices on farm]. Journal of International Development Studies, 28(1), 53-69. https://doi.org//10.32204/jids.28.1_53

Nishikawa, Y., \& Hamaguchi, M. (2018). Shushi wo meguru shimin soshiki noumin soshiki wo meguru kokusaiteki jokyo ni kansuru kousatsu [A preliminary study on global movement on seeds by civil society and farmers organizations: Perspective through participation in the 7 th Governing Body Meeting of the International Treaty on Plant Genetic Resources for Food and Agriculture]. The Journal of the Society for Studies on Economies and Societies, 58(3-4), 33-57. Retrieved July 26, 2021, from https://ci.nii.ac.jp/naid/120 006527940

Pimbert, M. P. (Ed.). (2018a). Food sovereignty, agroecology and biocultural diversity: Constructing and contesting knowledge. Routledge.

Pimbert, M. P. (2018b). Democratizing knowledge and ways of knowing for food sovereignty, agroecology and biocultural diversity. Food sovereignty, agroecology and biocultural diversity: Constructing and contesting knowledge (pp. 259-321). Routledge.

Rosset, P. M., \& Altieri, M. A. (2017). Agroecology: Science and politics. Fernwood Publishing.

Rosset, P. M., \& Martínez-Torres, M. E. (2012). Rural social movements and agroecology: Context, theory, and process. Ecology and Society, 17(3), 17. https://doi.org/10.5751/ES-05000-170317 
Scoones, I. (2015). Sustainable liveliboods and rural development. Agrarian Change \& Peasant Studies Series. Fernwood Publishing.

Shigeta, M. (1994). Kagakusha no hakken to nomin no ronri Afurika nogyo no toraekata [Way of knowing by scientists and rationale of farmers, perspectives for African agriculture]. In T. Inoue, O. Soda, \& K. Fukui (Eds.), Bunka no chibeisen [Perspectives of culture] (pp. 455-474). Sekai-Shiso Sha.

Sota, O. (2000). Nogaku genron [Philosophy of agriculture]. Iwanami Shoten.

Tsurumi, K. (1975). Yanagita Kunio's work as a model of endogenous development. In K. Tsurumi, The adventure of ideas: A collection of essays on patterns of creativity \& a theory of endogenous development. Manga University. Retrieved July 26, 2021, from www.howtodrawmanga.com/products/tsurumi

Tsurumi, K. (1996). Naihatsuteki hatten ron no keifu [Genealogy of endogenous development theory]. In K. Tsurumi \& T. Kawata (Eds.), Naibatsuteki hatten ron [Endogenous development theory] (pp. 43-64). University of Tokyo Press.

Une, Y. (2018). Noh no soko ni nagareru seishinsei no yutakasa: atarashi nohgaku wo hiraku [Wealth of spirituality flowing in agrarian practices: Towards new agricultural sciences]. Journal of Organic Agriculture, 10(1), 36-38. https://doi.org/10.24757/joas.10.1_16

Yamane, Y., \& Ito, K. (2019). Datsu kindaika shakai no jitsugen ni muketa nohgaku oyobi nohgyo gijutu shien no arikata [An ideal agricultural science and agricultural technological support for realization of de-modernization society]. Journal of International Development Studies, 28(1), 39-52. https:// doi.org/10.32204/jids.28.1_39

Open Access This chapter is licensed under the terms of the Creative Commons Attribution 4.0 International License (http://creativecommons.org/licenses/ by $/ 4.0 /)$, which permits use, sharing, adaptation, distribution and reproduction in any medium or format, as long as you give appropriate credit to the original author(s) and the source, provide a link to the Creative Commons license and indicate if changes were made.

The images or other third party material in this chapter are included in the chapter's Creative Commons license, unless indicated otherwise in a credit line to the material. If material is not included in the chapter's Creative Commons license and your intended use is not permitted by statutory regulation or exceeds the permitted use, you will need to obtain permission directly from the copyright holder.

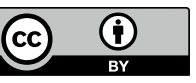

